\section{EFFECT OF AGAR-KAOLIN INTERACTION IN GELCASTING MIXTURES ON FORMING OF ALUMINA MEMBRANE SUPPORT}

Kowit Lertwittayanon*

Department of Materials Science and Technology, Faculty of Science, Prince of Songkla University, Hat Yai, Songkhla, 90110, Thailand
Article history

Received

14 October 2017

Received in revised form

30 December 2017

Accepted

1 March 2018

Published online

16 May 2018

\section{*Corresponding author}

kowit.l@psu.ac.th

\section{Graphical abstract}

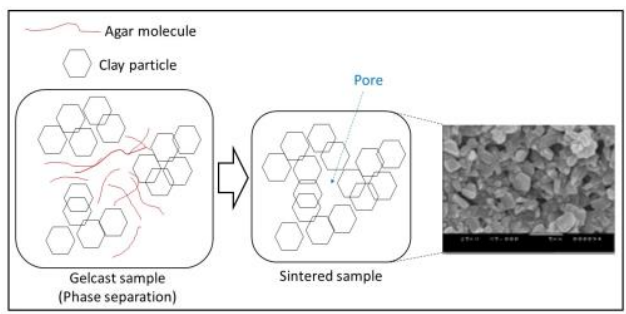

\begin{abstract}
Disc alumina membrane supports were formed through agar gelcasting method. The agar gelcasting was expected to be environmentally-friendly forming technique using simple equipment. Final agar amounts $(0.25-0.75 \mathrm{w}+\%)$ in gelcasting mixtures were varied to find the optimum condition of shaping and the desired microstructure of sintered supports. The gelcasting mixtures were prepared from non-reactive grade $\mathrm{Al}_{2} \mathrm{O}_{3}$ and porcelain at the ratio of 98.5:1.5 by weight. The porcelain addition allowed the membrane support to have high strength at lower sintering temperature. When the final agar amounts increased from 0.25 to $0.75 \mathrm{w}+\%$, the dried, gelcast supports tended to have rough surface and subsequently resulting in crack. TGA profiles confirmed that there was interaction between agar chains and kaolin particles on cooling the gelcast supports leading to different microstructures after sintering. The final agar amount of $0.5 \mathrm{w}+\%$ provided the highest porosity of $48.9 \%$ and the highest relative density of $61.5 \%$. Additionally, the average pore size of $1.5 \mu \mathrm{m}$ was obtained at the final agar amount of $0.5 \mathrm{w}+\%$ suitable for using as asymmetric membrane support or microfiltration membrane.
\end{abstract}

Keywords: Agar, gelcasting, ceramic, porous, membrane

(C) 2018 Penerbit UTM Press. All rights reserved

\subsection{INTRODUCTION}

Asymmetric ceramic membrane is usually used for industrial applications, especially for the heat-related and acid/base conditions [1, 2, 3]. In those conditions, polymeric membrane cannot withstand. As a result, the asymmetric ceramic membrane is still favourable, although its cost is high compared with the competitive material. For tubular ceramic membrane, the typical method of forming in large scale production and laboratory is extrusion method [4, 5]. However, the extrusion method needs an extruder offering continuous production and being easy-toform technique. However, the extruder is very expensive for ceramic factory. Therefore, a new forming method of ceramic membrane support through agar gelcasting is proposed in this work. The new method is expected to be practical alternative to forming tubular ceramic membrane without the extruder.

Agar is a polysaccharide extracted from red algae. Agar is a thermo-reversible and non-toxic gel; therefore, its usage is rather green process compared to conventional, toxic gelcasting $[6,7]$. In the development of ceramic fabrication process, agar is utilized for forming $\mathrm{Al}_{2} \mathrm{O}_{3}$ ceramics [8, 9, 10]. For forming $\mathrm{Al}_{2} \mathrm{O}_{3}$ ceramics, agar can be mixed with $\mathrm{Al}_{2} \mathrm{O}_{3}$ slurry in the form of agar solution at a temperature higher than its gelling temperature. The agar gelcasting is thoroughly studied on viscosity, drying shrinkage, green strength and density. Those properties 
are controlled by the concentration of agar solution and the final agar content. The positive feature of agar gelcasting is high green strength suitable for the step of green body machining instead of that of sintered body machining [9].

In addition to the aforementioned studies, drying method for agar gelcast sample need to be given attention. Since the drying method of agar gelcast sample occurs from so-called syneresis mechanismremoval of water from agar gel structure $[10,11]$. The syneresis of agar gel last for hours resulting in the deformation and cracking of agar gel due to stress development. Consequently, the drying stage plays a key role in gelcasting process indicating good formability without cracking.

Agar gelcasting offers the advantage of controllable microstructures for either dense or porous classifications [11, 14]. However, membrane pores are typically created from interparticle void. In the case of $\mathrm{Al}_{2} \mathrm{O}_{3}$ membrane, reactive grade $\mathrm{Al}_{2} \mathrm{O}_{3}$ powder is needed for sintering $\mathrm{Al}_{2} \mathrm{O}_{3}$. Therefore, the prepared membrane possesses the specific pore size and strength depending mainly upon the particle size of sinterable $\mathrm{Al}_{2} \mathrm{O}_{3}$ powder.

In this work, non-reactive grade $\mathrm{Al}_{2} \mathrm{O}_{3}$ was used for preparing membrane support by agar gelcasting. The use of non-reactive grade was to the reduction of cost. To keep mechanical properties of $\mathrm{Al}_{2} \mathrm{O}_{3}$ membrane support, porcelain-composition powder was used as sintering aid-liquid phase sintering. Therefore, glassy phase from the sintering aid was expected to bind the non-reactive grade $\mathrm{Al}_{2} \mathrm{O}_{3}$ together. The pore size created should be the void between the used $\mathrm{Al}_{2} \mathrm{O}_{3}$ particles larger than the usual. The small amount of porcelain was added at $1.5 \mathrm{w}+\%$ in order to maintain the $\mathrm{Al}_{2} \mathrm{O}_{3}$ featured properties. Final agar amounts were varied from 0.25 to $0.75 \mathrm{wt} \%$. The gelcast membrane supports were examined with XRD and TGA. The sintered membrane supports were tested by SEM. The porosity of sintered supports was determined by Achimedes' method. The results from SEM images showed the characteristic pores resulting from interactions between agar chains and kaolin particles contained in the porcelain powder. The pore sizes occurred from the interaction were different from the expected pore sizes resulting from void between particles.

\subsection{METHODOLOGY}

\subsection{Preparation of Gelcasting Mixture}

Two main preparations were carried out, i.e. $\mathrm{Al}_{2} \mathrm{O}_{3}$ slurry and agar solution. The separate preparations were to make the complete dissolution of agar powder leading to the achievement in homogeneous mixture of alumina slurry and agar solution. Raw materials used for preparing $\mathrm{Al}_{2} \mathrm{O}_{3}$ slurry consisted of $\mathrm{Al}_{2} \mathrm{O}_{3}$ powder and porcelain-proportioning powder. Low cost $\mathrm{Al}_{2} \mathrm{O}_{3}$ powder (A-325, non-reactive grade, Thai supplier) with particle size of less than $44 \mu \mathrm{m}$ was used. Ranong kaolin, potassium feldspar and silica purchased from Thai suppliers were mixed at 50:25:25 by weight percent for preparing porcelain powder. The amount of porcelain powder was fixed at $1.5 \mathrm{w}+\%$ functioning as the binder of $\mathrm{Al}_{2} \mathrm{O}_{3}$ particles. All the powder was ball milled for $24 \mathrm{~h}$ in porcelain jar using $\mathrm{Al}_{2} \mathrm{O}_{3}$ ball. The $\mathrm{Al}_{2} \mathrm{O}_{3}$ slurry was prepared at 75 wt\% total solid loading. Ammonium salt of polyacrylic acid was used as dispersant at $0.07 \mathrm{wt \%}$ of the total solid being determined from deflocculant curve.

\subsection{Gelcasting of $\mathrm{Al}_{2} \mathrm{O}_{3}$ Membrane Support}

Agar solution was prepared from boiling agar powder (Thai supplier) at $2 \mathrm{w}+\%$ concentration in distilled water. The agar solution was mixed with the prepared $\mathrm{Al}_{2} \mathrm{O}_{3}$ slurry maintained at $50^{\circ} \mathrm{C}$. The agar solution was mixed at different amounts to obtain different final agar amounts at $0.25,0.50$ and $0.75 \mathrm{w}+\%$ of total solid. The warm $\mathrm{Al}_{2} \mathrm{O}_{3}$ mixtures were gel-cast into PVC ring (diameter of $50 \mathrm{~mm}$ and thickness of $3 \mathrm{~mm}$ ) to obtain disc green support with $3 \mathrm{~mm}$ thickness. The gelcast mixtures were soaked in a solvent for $1 \mathrm{~h}$ to make solvent-exchange drying condition. In other words, it was to make syneresis of agar gel. The soaked gelcasting samples were removed from the solvent leading to rapid drying at room temperature. The dried samples were sintered at 1400 and $1450^{\circ} \mathrm{C}$ for 1 h.

\subsection{Characterizations}

The gelcast samples were examined with XRD (Philips Xpert MPD) and TGA for phase analyses and weight losses, respectively. The weight losses were expected to appear some interactions between the solid particles and agar chains. The TGA measurement was carried out in $\mathrm{N}_{2}$ atmosphere at the heating rate of $10^{\circ} \mathrm{C} / \mathrm{min}$. The measurement in $\mathrm{N}_{2}$ atmosphere helped in analysis related water-particles-agar interactions. The more detail of interactions might appear the coexistence of solid particles and agar chains. The sintered samples were characterized by XRD and SEM (JEOL JSM-5200). The average pore size was estimated by using SEM images. Porosity, water adsorption and relative density of samples were characterized by Archimedes' method.

\subsection{RESULTS AND DISCUSSION}

The gelcast green $\mathrm{Al}_{2} \mathrm{O}_{3}$ membrane support with different final agar amounts were fabricated as shown in Figure 1. The cracked green sample was a representative sample of $30 \%$ cracking from 10 samples. The photos of gelcasting green samples showed the trend of formability resulting in the cracking when the final agar amount reached 0.75 $w+\%$. The result suggested that using larger amount of final agar has negative effect on the gelcast formability. 
Figure 2(a) displays the weight losses with temperature of green samples indicating some interaction between agar chains and solid particles; while Figure 2(b) shows the weight loss of agar powder with temperature. Apparently, agar powder losses its weight at about 100 and $260^{\circ} \mathrm{C}$ relating to the removal of moisture and agar chains. When the agar chains co-existed with solid particles, the trend of weight losses was rather complicated. Interestingly, the total weight losses of green samples were not parallel with increasing final agar amounts, i.e. 2.2, 2.9 and $1.4 \mathrm{wt} \%$ for the final agar amounts of $0.25,0.5$ and $0.75 \mathrm{wt} \%$, respectively. The results implied that there were some interactions between agar chains and solid particles within the range of final agar amounts studied in this work. The assumption was confirmed from nearly the same moisture removal for all the green supports. Therefore, the ratio of agar:solid particles had significant effect on the existing interactions. A study reported that there were different interactions between agar chains and cationic or anionic surfactant including non-ionic surfactant [15]. As a result, the different ratios of agar:solid particles might provide different interactions leading to different microstructures of sintered membrane supports.
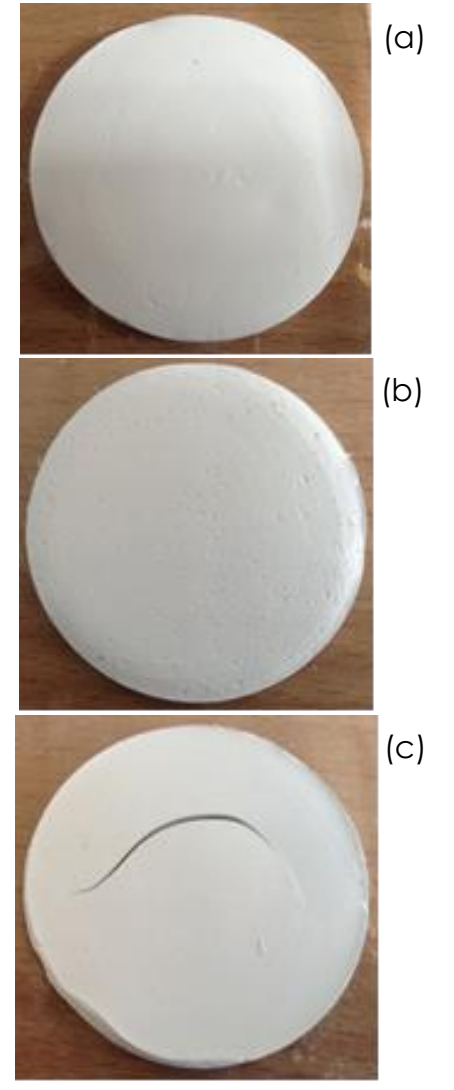

Figure 1 Photos of green gelcast membrane supports prepared from the mixtures with different final agar amounts at (a) 0.25 , (b) 0.50 and (c) $0.75 \mathrm{w}+\%$ of total solid

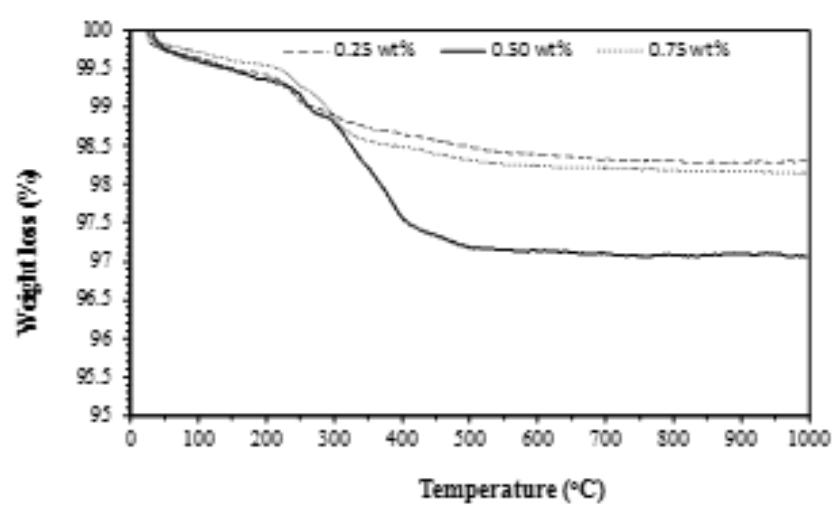

(a)

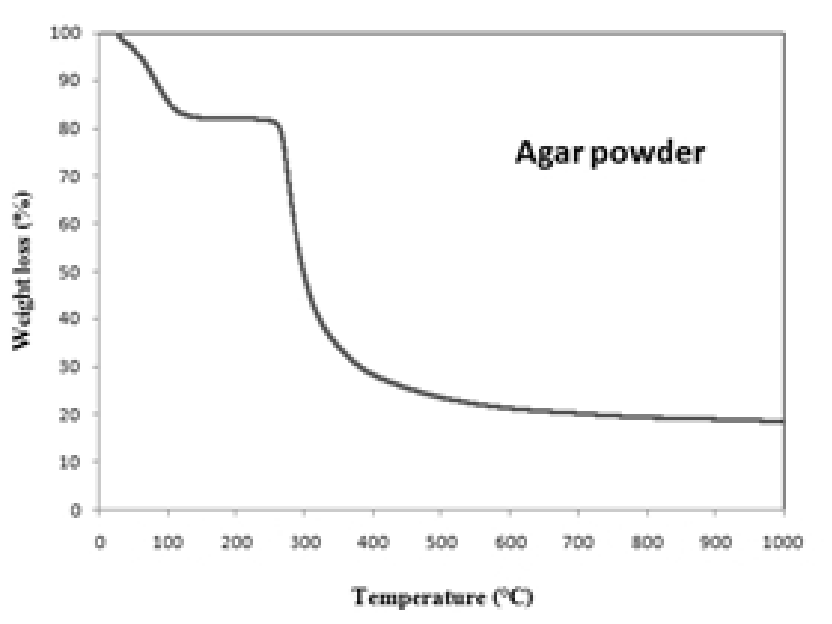

(b)

Figure 2 TGA profiles of (a) gelcast green membrane support and (b) agar powder from 30 to $1000^{\circ} \mathrm{C}$ in $\mathrm{N}_{2}$ atmosphere at heating rate of $10^{\circ} \mathrm{C} / \mathrm{min}$

Figure 3 indicate XRD patterns of all the gelcast green membrane supports. All the XRD patterns showed the presence of $\mathrm{a}-\mathrm{Al}_{2} \mathrm{O}_{3}$, kaolin and quartz phases. However, there was no phase of potassium feldspar. The result might be due to detection limit of XRD. Too small amount of potassium feldspar was undetectable with XRD. Interestingly, there was unknown peak for all the green membrane supports at $2 \theta$ of $8^{\circ}$. The insert in Figure 3 displayed clearer peaks for the unknown phase. The unknown peak occurring at $<10^{\circ}$ was attributed to the nature of layer-by-layer clay. The interlayer distance corresponded with $d$ spacing leading to diffracting X-ray at $2 \theta$ of $<10^{\circ}$ when it was calculated from Scherrer's equation [16]. The result indicted that kaolin particles were arranged into layer-by-layer way when the particles were coexisted with agar chains during gelation.

Figure 4 shows XRD patterns of all the sintered membrane supports. The results indicated the existence of only $\mathrm{a}-\mathrm{Al}_{2} \mathrm{O}_{3}$ phase. Due to too small amount of the other phases after sintering, the other phases were undetectable by XRD. 


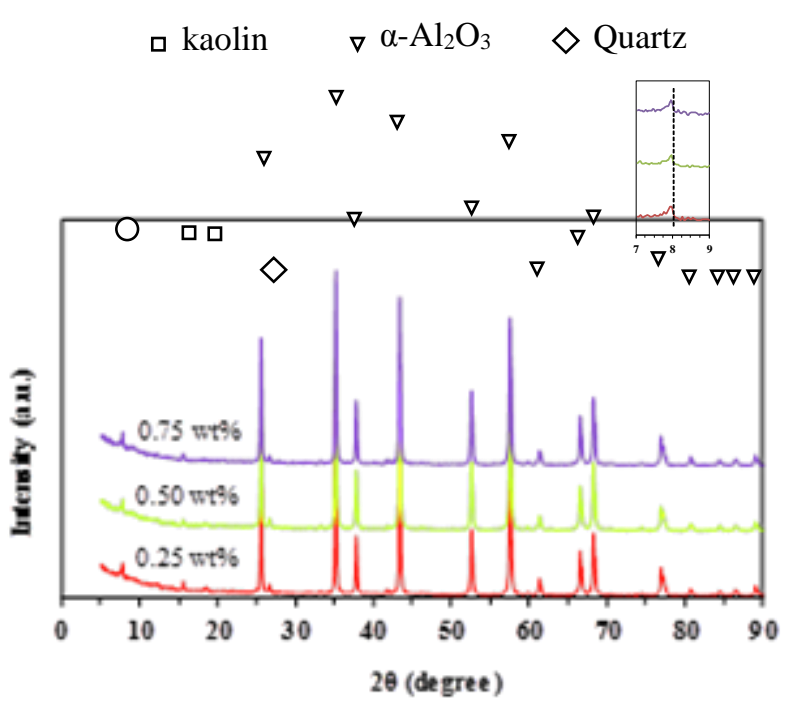

Figure 3 XRD patterns of green gelcast membrane supports prepared from the mixtures with different final agar amounts

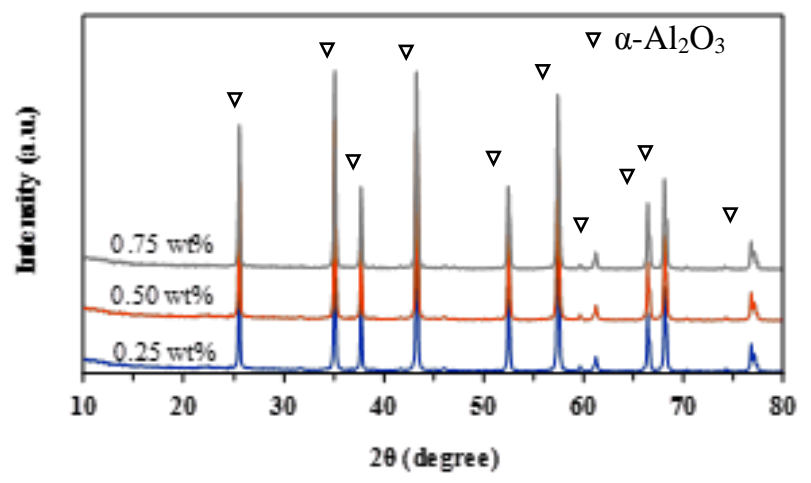

Figure 4 XRD patterns of sintered gelcast membrane supports prepared from the mixtures with different final agar amounts

The physical properties related to support membrane application, i.e. porosity, water adsorption and relative density were shown in Table 1. From all the results of porosity, after sintering at $1450^{\circ} \mathrm{C}$ membrane support containing $0.50 \mathrm{w}+\%$ showed the highest porosity of $48.9 \%$. When considering the further property, i.e. water adsorption, at $0.50 \mathrm{w}+\%$ final agar amount membrane support offered the highest water adsorption of $20.2 \%$ corresponding with its porosity.
Table 1 Porosity, water adsorption, relative density of sintered membrane supports after sintering at 1400 and $1450^{\circ} \mathrm{C}$

\begin{tabular}{ccccccc}
\hline $\begin{array}{c}\text { Final agar } \\
\text { amount }\end{array}$ & Porosity (\%) & \multicolumn{2}{c}{$\begin{array}{c}\text { Water } \\
\text { adsorption } \\
\text { (\%) }\end{array}$} & \multicolumn{2}{c}{$\begin{array}{c}\text { Relative } \\
\text { density } \\
\text { (\%) }\end{array}$} \\
\cline { 2 - 7 } & $\mathbf{1 4 0 0}$ & $\mathbf{1 4 5 0}$ & $\mathbf{1 4 0 0}$ & $\mathbf{1 4 5 0}$ & $\mathbf{1 4 0 0}$ & $\mathbf{1 4 5 0}$ \\
\hline $0.25 \mathrm{w}+\%$ & 35.0 & 25.1 & 15.0 & 10.0 & 59.0 & 65.0 \\
\hline $0.50 \mathrm{w}+\%$ & 34.5 & 48.9 & 14.5 & 20.2 & 61.5 & 61.5 \\
\hline $0.75 \mathrm{w}+\%$ & 36.0 & 36.0 & 16.7 & 16.1 & 55.0 & 53.8 \\
\hline
\end{tabular}

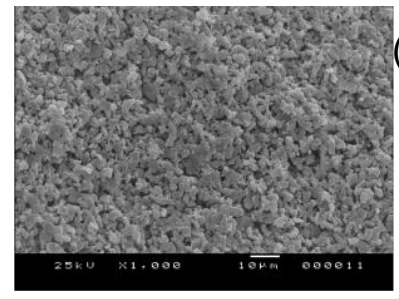

(a)

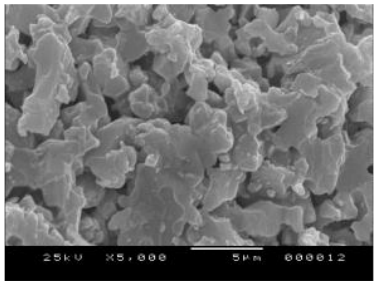

(b)
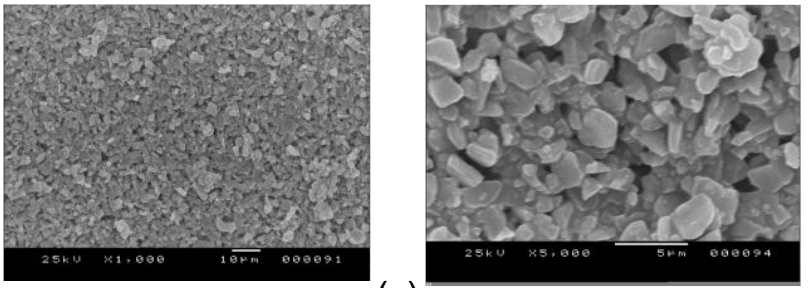

(c)
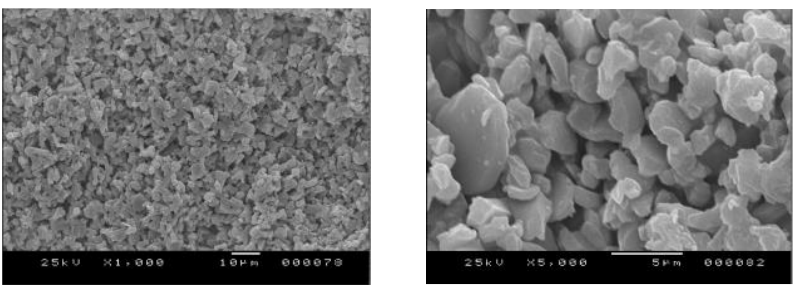

Figure 5 SEM images of sintered membrane supports after sintering at $1450^{\circ} \mathrm{C}$ for final agar amounts of (a) $0.25 \mathrm{wt \%}$, (b) $0.50 w+\%$ and (c) $0.75 w+\%$ at the magnification of $1000 x$ (left, $10 \mu \mathrm{m}$ scale bar) and 5000x (right, $5 \mu \mathrm{m}$ scale bar)

Additionally, its relative density was rather high as well. Consequently, containing $0.50 \mathrm{w}+\%$ final agar amount met the requirement for membrane application compared with the other membrane supports.

Figure 5 shows SEM images of sintered gelcast membrane support at two magnifications, i.e. 1000x and 5000x. Clearly, the microstructure of sintered membrane supports was different when final agar amounts increased from 0.25 to $0.75 \mathrm{wt} \%$. The average pore size for only the membrane support containing 0.5 wt\% final agar amount was determined from its SEM image since the two another membrane supports showed no measurable pores. The average pore size for $0.50 \mathrm{w}+\%$ final agar amount was about $1.5 \mu \mathrm{m}$. All the microstructures were parallel with their physical properties. The microstructures confirmed that there were different 
interactions for the different ratios of agar:solid particles. From further consideration on the interaction, it was assumed that agar chains and kaolin particles had interaction together. Since kaolin has negative surface charge and positive sidesurface charge, it interacted with agar chains having negative charge on their side chains. Therefore, the different ratios of agar:kaolin affected the microstructure of membrane supports after gelation of agar leading to final different microstructures after sintering. The SEM images revealed thermodynamic equilibrium creating different pore shapes. In other words, their optimum ratio formed phase separation in different ways. Too many amounts of agar resulted in severe phase separation responsible for the cracking during drying and rough texture after sintering. However, the finding of phase separation differed from the case of using porcelain body for forming through aqueous injection molding [17]. In other words, there was no phase separation appeared when only porcelain body was used for gelcasting. The different results might be related to the whole amount of porcelain for the injection molding and only the small amount of porcelain for the gelcasting in this work.

From further literature reviews on the interaction between agar chains (biopolymer) and kaolin (clay) particles, it was found that their interaction was parallel with the polymer-clay interactions, i.e., intercalation, exfoliation and phase separation [18, 19, 20]. The mechanism of phase separation confirmed the root of porous microstructure accidentally obtained in this work. However, the root of phase separation was complicated since there were several factors related to the interactions between clay and polymer composites such as types and amount of clay and polymer, preparation methods, etc. Therefore, useful characterizations need to be carried out further to confirm the existing interactions leading to controllable microstructures.

\subsection{CONCLUSION}

Disc $\mathrm{Al}_{2} \mathrm{O}_{3}$ membrane supports were formed by agar gelcasting. The porcelain-proportioning powder was added to $\mathrm{Al}_{2} \mathrm{O}_{3}$ slurry to bind the non-reactive grade $\mathrm{Al}_{2} \mathrm{O}_{3}$ leading to densification of $\mathrm{Al}_{2} \mathrm{O}_{3}$. The results showed that the final agar amounts had considerable effect on the co-existence with kaolin contained in porcelain. The different ratios of agar:kaolin offered the form of different phase separation leading various pore size and shape within the microstructure of membrane supports. The pore sizes occurred in this work were rather large differing from typical membrane support generated from the interparticle space.

\section{Acknowledgement}

This research is supported by grant number SCI560410S, 2013, Prince of Songkla University (PSU). The author would like to thank Membrane Science and Technology Research Center (MSTRC), PSU for partial support in this research work.

\section{References}

[1] Jeong, Y., Cho, K., Kwon, E. E., Tsang, Y. F., Rinklebe, J., Park, C. 2017. Evaluating the Feasibility of PyrophylliteBased Ceramic Membranes for Treating Domestic Wastewater in Anaerobic Ceramic Membrane Bioreactors. Chemical Engineering Journal. 328(7): 567573.

DOI: https://doi.org/10.1016/j.cej.2017.07.080.

[2] Li, W., Ling, G., Lei, F., Li, N., Peng, W., Li, K., Lu, H., Hang, F., Zhang, Y. 2018. Ceramic Membrane Fouling and Cleaning During Ultrafiltration of Limed Sugarcane Juice. Separation and Purification Technology. 190(26): 9-24. DOI: $\mathrm{https}: / /$ doi.org/10.1016/j.seppur.2017.08.046.

[3] Song, I. H., Bae, B. S., Ha, J. H., Lee, J. 2017. Effect of Hydraulic Pressure on Alumina Coating on Pore Characteristics of Flat-Sheet Ceramic Membrane. Ceramics International. 43(13): 10502-10507. DOI: https://doi.org/10.1016/j.ceramint.2017.05.098.

[4] Oun, A., Tahri, N., Chergui, S. M., Carbonnier, B., Majumdar, S., Sarkar, S., Sahoo, G. C., Amar, R. B. 2017. Tubular Ultrafiltration Ceramic Membrane Based on Titania Nanoparticles Immobilized on Macroporous Clay-Alumina Support: Elaboration, Characterization and Application to Dye Removal. Separation and Purification Technology. 188: 126-133. DOI: https://doi.org/10.1016/j.seppur.2017.07.005.

[5] Almandoz, M. C., Pagliero, C. L., Ochoa, N. A., Marchese, J. 2015. Composite Ceramic Membranes from Natural Aluminosilicates for Microfiltration Applications. Ceramics International. 41 (4): 5621-5633.

DOI: https://doi.org/10.1016/j.ceramint.2014.12.144.

[6] Guo, L., Yang, J., Feng, Y., Qiu, T. 2018. Non-Aqueous Gelcasting of AIN Ceramics Using a Low-Toxicity Monomer (DMAA) as Gelling Agent. Ceramics International. 44(2): 1621-1626.

DOI: https://doi.org/10.1016/j.ceramint.2017.10.083.

[7] Zhang, C., Yang, J., Qiu, T. 2012. Preparation of ZTA Ceramic by Aqueous Gelcasting with a Low-Toxic Monomer DMAA. Ceramics International. 38(4): 3063-3068. DOI: https://doi.org/10.1016/j.ceramint.2011.12.004.

[8] Millán, A. J., Moreno, R., Nieto, M. I. 2002. Thermogelling Polysaccharides for Aqueous Gelcasting-Part I: A Comparative Study of Gelling Additives. Journal of European Ceramic Society. 22(13): 2209-2215. DOI: https://doi.org/10.1016/S0955-2219(01)00532-5.

[9] Millán, A. J., Nieto, M. I., Baudín, C., Moreno, R. 2002. Thermogelling Polysaccharides for Aqueous GelcastingPart II: Influence of Gelling Additives on Rheological Properties and Gelcasting of Alumina. Journal of European Ceramic Society. 22(13): 2217-2222. DOl: https://doi.org/10.1016/S0955-2219(01)00533-7.

[10] Millán, A. J., Nieto, M. I., Moreno, R., Baudín, C. 2002. Thermogelling Polysaccharides for Aqueous GelcastingPart III: Mechanical and Microstructural Characterization of Green Alumina Bodies. Journal of European Ceramic Society. 22(13): 2223-2230. DOI: https://doi.org/10.1016/S0955-2219(01)00534-9.

[11] Munro, C. D., Plucknett, K. P. 2011. Agar-Based Aqueous Gel Casting of Barium Titanate Ceramics. International Journal of Applied Ceramic Technology. 8(13): 597-609. DOI: https://doi.org/10.1111/j.1744-7402.2009.02466.x. 
[12] Boral. S., Saxena. A., Bohidar. H. B. 2010. Syneresis in Agar Hydrogels. International Journal of Biological Macromolecules. 46(2): 232-236.

DOI: https://doi.org/10.1016/j.ijbiomac.2009.12.008.

[13] Matsukawa, S., Ding, Y., Zhao, Q., Mogi, A., Tashiro, Y., Ogawa, H. 2014. Effect of Solvent Transfer in Agar Gels on Stress Relaxation under Large Deformation. Carbohydrate Polymers. 109: 166-170.

DOI: https://doi.org/10.1016/j.carbpol.2014.03.055.

[14] Potoczek, M. 2008. Gelcasting of Alumina Foams Using Agarose Solutions. Ceramics International. 34(3): 661-667. DOI: https://doi.org/10.1016/j.ceramint.2007.02.001.

[15] Prasad, K., Siddhanta, A. K., Rakshit, A. K., Bhattacharya A., Ghosh, P. K. 2005. On the Properties of Agar Gel Containing Ionic and Non-ionic Surfactants. International Journal of Biological Macromolecules. 35(10): 135-144. DOI: https://doi.org/10.1016/j.jibiomac.2005.01.004.

[16] Bristow, T. F., Bish, D. L., Vaniman, D. T., Morris, R. V., Blake D. F., Grotzinger, J. P., Rampe, E. B., Crisp, J. A., Achilles, C. N., Ming, D. W., Ehlmann, B. L., King, P. L., Bridges, J. C. Eigenbrode, J. L., Sumner, D. Y., Chipera, S. J., Moorokian J. M., Treiman, A. H., Morrison, S. M., Downs, R. T., Farmer, J.
D., Marais, D. D., Sarrazin, P., Floyd, M. M., Mischna, M. A., McAda, A. C. 2015. The Origin and Implications of Clay Minerals from Yellowknife Bay, Gale Crater, Mars. The American Mineralogist. 100(13): 824-836.

[17] Santacruz I., Nieto M. I., Moreno R., Ferrandino P. Salomoni A., Stamenkovic I. 2003. Aqueous Injection Moulding of Porcelains. Journal of European Ceramic Society. 23(12): 2053-2060.

DOI: https://doi.org/10.1016/S0955-2219(03)00018-9.

[18] Chen, B. 2004. Polymer-Clay Nanocomposites: an Overview with Emphasis on Interaction mechanisms. British Ceramic Transaction. 103 (6): 241-249.

DOI: https://doi.org/10.1179/096797804X4592.

[19] Pinnavaia, T. J., Beall G. W. 2001. Polymer-Clay Nanocomposites. Wiley

[20] Sikdar, D., Katti, D. R., Katti, K. S. 2008. The Role of Interfacial Interactions on the Crystallinity and Nanomechanical Properties of Clay-Polymer Nanocomposites: A Molecular Dynamics Study. Journal of Applied Polymer Science.107 (5): 3137-3148. DOI: http://dx.doi.org/10.1002/app.27504. 